\title{
Dental Aesthetic Index among Nepalese Orthodontic Patients
}

\author{
Dr Rabindra Man Shrestha, ${ }^{1}$ Dr Bikash Lamichhane, ${ }^{2}$ Dr Anuj Kumar Sharma, ${ }^{3}$ Dr Sujita Shrestha ${ }^{4}$ \\ 'Associate Professor, Dept of Orthodontics, ${ }^{4}$ Lecturer, Dept of Community \& Public Health Dentistry \\ Kantipur Dental College, Kathmandu, Nepal \\ 2.3Dental Surgeon
}

Correspondence: Dr Rabindra Man Shrestha; Email: rabindraortho@gmail.com

\section{ABSTRACT}

Introduction: Orthodontic indices are used for the assessment of malocclusion, its severity level, and treatment need. Dental Aesthetic Index (DAI) is a simple, valid and reliable index commonly used for epidemiological survey and initial screening of the orthodontic patients.

Objective: To evaluate the frequency and severity of malocclusion and orthodontic treatment need among Nepalese patients using DAI and to compare the treatment need between gender groups.

Materials \& Method: 150 pairs of maxillary and mandibular pre-treatment orthodontic study models of 59 male and 91 female patients with permanent dentition were randomly selected from the Department of Orthodontics, Kantipur Dental College. Ten occlusal traits of DAI were assessed on each pair of study models using graduated periodontal probe and metallic scale by a single examiner. Cumulative DAI scores were calculated according to standard DAI method to differentiate the severity of malocclusion and orthodontic treatment need.

Result: About $60 \%$ of the sample presented severe or very severe (handicapping) malocclusions indicating highly desirable or mandatory treatment need. $21.3 \%$ had definite malocclusion that required elective treatment need, $19.3 \%$ had normal occlusion with no or slight treatment need. There was no statistically different mean DAl scores between male and female samples $(p=0.116)$

Conclusion: Most of the samples were in great need of orthodontic treatment with very severe malocclusions. Male samples had greater percentage of 'very severe' malocclusion than female. Malocclusion was characterized with high frequency of anterior incisal irregularity, maxillary overjet, midline diastema. DAI can be used as a screening tool rather than the decision making tool.

Key words: Dental Aesthetic Index, orthodontics, treatment need

\section{INTRODUCTION}

Malocclusion is defined as the irregularity of teeth or malrelationship of the dental arches beyond the normal. It is the third most common dental health problem worldwide concerning with facial esthetics, dental appearance and dental health of the people. ${ }^{1,2}$ Occlusal indices are the methods to determine the amount of deviation from normal occlusion; frequency, severity and level of treatment need among individual patient or population. ${ }^{3}$ Many occlusal indices have been proposed to categorize the malocclusion frequency, severity and treatment need. ${ }^{4}$

Dental Aesthetic Index (DAI) was introduced by Cons et al in 1986 as an epidemiological tool to rank dental esthetics and orthodontic treatment need on a scale of social norms for a socially acceptable dental appearance which links mathematical, objective (occlusal), clinical, and subjective esthetic factors to produce a single score that reflects the severity and the treatment needs of the malocclusion..$^{5-9}$ Considering the societally defined norms for dental appearance and recognizing the conditions that are potentially psycho-socially handicapping; DAI highlights the importance of physical attractiveness. ${ }^{3}$ It was integrated into the International Collaboration Study of Oral Health Outcomes by World Health Organization as an objective, simple, easily applied, valid and reliable cross-cultural index. ${ }^{6.7}$ It is used as a screening device in epidemiological survey. DAl allows dental public health and orthodontic insurance programs to screen and identify persons eligible for such programs on the basis of their esthetic needs. DAl does not necessarily require a specialist; thus it can be carried out with limited resources and is proven to be efficient in resource management. ${ }^{8}$

DAI involves ten occlusal traits which lead to aesthetic and social problems to patients and are among the 
Chart 1: DAl scoring criteria

\begin{tabular}{|l|l|l|}
\hline DAI Score & \multicolumn{1}{|c|}{ Severity Level } & \multicolumn{1}{c|}{ Treatment Need } \\
\hline$\leq 25$ & Normal or minor malocclusion & No treatment need or slight need \\
\hline $26-30$ & Definite malocclusion & Treatment elective \\
\hline $31-35$ & Severe malocclusion & Treatment highly desirable \\
\hline$\geq 36$ & Very severe (handicapping) malocclusion & Treatment mandatory \\
\hline
\end{tabular}

common complaints with which the patients come for orthodontic treatment.' The objective of the study was to assess malocclusion severity level and orthodontic treatment need in referred Nepalese orthodontic patients using Dental Aesthetic Index (DAI).

\section{MATERIALS AND METHOD}

A total of randomly selected 150 pre-treatment study models of 91 female and 59 male were collected from the Department of Orthodontics, Kantipur Dental College Teaching Hospital \& Research Center, Kathmandu. The study was conducted during April-June 2015. The study was designed as an observational, retrospective, crosssectional study. Good quality pre-treatment study models having unbroken teeth were chosen for the study. The study models of the orthodontic patients with permanent dentition having all teeth fully erupted (except third molar) were included in the study. Any study model of orthodontically pre-treated cases and patients with congenital anomaly were excluded from the study.

DAl consists of 10 occlusal traits related to dentofacial anomalies assessing the dentition, spacing and occlusion. The ten occlusal traits include: number of missing teeth (incisor, canine, premolar), crowding in the incisal segment, spacing in the incisal segment, midline diastema, largest anterior irregularity in maxilla, largest anterior irregularity in mandible, anterior maxillary overjet, anterior mandibular overjet, vertical anterior open bite and antero-posterior molar relationship.

DAl components were assessed by a single examiner from each pair of study models using graduated periodontal probe and metallic scale. The findings were recorded in a predetermined performa to evaluate total DAI score. Obtained component scores were multiplied with calculated weight of standard DAI method to find the cumulative DAl score to differentiate the severity of malocclusion and orthodontic treatment need.

DAI score was calculated using the regression equation of 10 occlusal traits: "(visible missing teeth $\times 6$ ) + (crowding) $+($ spacing $)+($ midline diastema $\times 3)+($ anterior maxillary irregularity) + (anterior mandibular irregularity) + (anterior maxillary overjet $\times 4)+($ anterior mandibular overjet $\times 4)+$ (anterior vertical open bite $\times 4$ ) + (antero-posterior molar relationship $\times 3$ ) + 13(constant)"., 1,2, Obtained score were recorded on DAl score chart. Chart 1 shows the reference for DAl scoring criteria classification.

Pretest was done on 10 study models by the single examiner at the interval of one week. The attained reliability (kappa value 0.86 intra-class correlation coefficient) was in agreement with the recommended standards. Statistical analyses were done using SPSS Version 20; descriptive statistical data were calculated for DAl scores and occlusal traits. Gender variation was compared using chi-square test with the significance level of $p<0.05$.

\section{RESULT}

The study sample consisted of 150 pre-treatment orthodontic study models in which $60.66 \%$ belonged to female patients. The DAl scores obtained from the present study ranged from 19 to 62 , with the mean DAI score 34.59 (SD 9.88). Anterior incisal segments irregularity, maxillary overjet, and midline diastema were found to be of higher prevalence among all occlusal traits. The frequency distribution of each occlusal trait is shown in Table 1. According to the study; $43.3 \%$ had very severe handicapping malocclusion with mandatory treatment need, $16.0 \%$ had severe malocclusion with highly desirable treatment need, $21.3 \%$ had definite malocclusion that required elective treatment need, $19.3 \%$ of population had normal occlusion with no or slight treatment need (Table 2, Figure 1).

Male samples had higher occurrence of very severe (handicapping) malocclusion with $52.5 \%$ requiring mandatory treatment compared to female with $37.4 \%$ requiring mandatory treatment. $23.7 \%$ male samples had definite malocclusion with elective treatment need while 19.8\% female had elective treatment need. $13.6 \%$ male samples had normal occlusion or minor malocclusion with no/slight treatment need compared to $23.1 \%$ females (Table 2, Figure 2). 
Table 1: Frequency distribution of each DAl component

\begin{tabular}{|c|c|c|c|}
\hline Occlusal trait & Grading & Frequency & Percentage \\
\hline $\begin{array}{l}\text { Number of missing teeth: The number of missing } \\
\text { permanent incisors, canines and premolars in the upper } \\
\text { and lower arches was recorded. Excludes clinically } \\
\text { missing teeth if the spaces were closed with the } \\
\text { remaining teeth, retained deciduous teeth and fixed } \\
\text { prosthesis. }\end{array}$ & $\geq 1$ & 16 & $10.66 \%$ \\
\hline $\begin{array}{l}\text { Crowding in incisal segments: Insufficient spaces } \\
\text { between the canines to accommodate the incisors } \\
\text { causing either rotations or displacements. }\end{array}$ & $\begin{array}{l}0=\text { No crowding } \\
1=1 \text { segment crowded } \\
2=2 \text { segment crowded }\end{array}$ & $\begin{array}{l}24 \\
49 \\
77\end{array}$ & $\begin{array}{c}16 \% \\
32.66 \% \\
51.33 \%\end{array}$ \\
\hline $\begin{array}{l}\text { Spacing in incisal segments: Visually seen spaces } \\
\text { including midline diastema were included. }\end{array}$ & $\begin{array}{l}0=\text { No spacing } \\
1=1 \text { segment spacing } \\
2=2 \text { segment spacing }\end{array}$ & $\begin{array}{c}101 \\
41 \\
8\end{array}$ & $\begin{array}{c}67.33 \% \\
27.33 \% \\
5.33 \%\end{array}$ \\
\hline $\begin{array}{l}\text { Midline diastema (in } \mathrm{mm} \text { ): Space between two maxillary } \\
\text { incisors in } \mathrm{mm} \text {. }\end{array}$ & $\geq 1 \mathrm{~mm}$ & 26 & $17.33 \%$ \\
\hline $\begin{array}{l}\text { Anterior maxillary irregularity (in } \mathrm{mm} \text { ): Rotations or } \\
\text { displacements of the maxillary incisors from normal } \\
\text { alignment with or without crowding is measured in } \mathrm{mm} \text {. }\end{array}$ & $\begin{array}{l}\text { No irregularity } \\
>0-3 \mathrm{~mm} \text { irregularity } \\
>3 \mathrm{~mm} \text { irregularity }\end{array}$ & $\begin{array}{c}2 \\
76 \\
72\end{array}$ & $\begin{array}{c}1.33 \% \\
50.66 \% \\
48 \%\end{array}$ \\
\hline $\begin{array}{l}\text { Anterior mandibular irregularity (in } \mathrm{mm} \text { ): Rotations or } \\
\text { displacements of the mandibular incisors from normal } \\
\text { alignment with or without crowding is measured in } \mathrm{mm} \text {. }\end{array}$ & $\begin{array}{l}\text { No irregularity } \\
>0-3 \mathrm{~mm} \text { irregularity } \\
>3 \mathrm{~mm} \text { irregularity }\end{array}$ & $\begin{array}{c}14 \\
111 \\
25\end{array}$ & $\begin{array}{l}9.33 \% \\
74 \% \\
16.66 \%\end{array}$ \\
\hline $\begin{array}{l}\text { Maxillary overjet (in } \mathrm{mm} \text { ): Distance between the labio- } \\
\text { incisal edge of the most prominent upper incisors to the } \\
\text { labial surface of the corresponding lower incisor with the } \\
\text { teeth in centric occlusion was measured in } \mathrm{mm} \text {. }\end{array}$ & $\begin{array}{l}0-3 \mathrm{~mm} \text { overjet } \\
>3 \mathrm{~mm} \text { overjet }\end{array}$ & $\begin{array}{l}80 \\
70\end{array}$ & $\begin{array}{l}53.33 \% \\
46.66 \%\end{array}$ \\
\hline $\begin{array}{l}\text { Mandibular overjet (in mm): Distance between the } \\
\text { linguo-incisal edge of the most prominent lower incisors } \\
\text { to the labial surface of the corresponding upper incisors } \\
\text { was measured in mm. A single tooth in crossbite was not } \\
\text { considered. }\end{array}$ & $>0 \mathrm{~mm}$ overjet & 8 & $5.33 \%$ \\
\hline $\begin{array}{l}\text { Anterior open bite (in } \mathrm{mm} \text { ): Lack of vertical over-lap } \\
\text { between any of the opposing incisors in } \mathrm{mm} \text {. }\end{array}$ & $>0 \mathrm{~mm}$ open bite & 5 & $3.33 \%$ \\
\hline $\begin{array}{l}\text { AP molar relationship: Abnormal molar relationship with } \\
\text { largest deviation from Angle Class I were assessed on } \\
\text { both sides with the teeth in proper occlusion. }\end{array}$ & $\begin{array}{l}0=\text { Normal } \\
1=\text { Half cusp either } \\
\text { mesial or distal } \\
2=\text { One full cusp either } \\
\text { mesial or distal }\end{array}$ & $\begin{array}{l}61 \\
41 \\
48\end{array}$ & $\begin{array}{c}40.66 \% \\
27.33 \% \\
32 \%\end{array}$ \\
\hline
\end{tabular}

Table 2: Distribution of sample according to DAl treatment need

\begin{tabular}{|c|c|c|c|c|}
\hline \multirow{2}{*}{ Sample } & \multicolumn{4}{|c|}{ DAl Treatment Need } \\
\cline { 2 - 5 } & No/Slight treatment need & Treatment elective & Treatment highly desirable & Treatment mandatory \\
\hline Female $(\mathrm{N}=91)$ & $21(23.1 \%)$ & $18(19.8 \%)$ & $18(19.8 \%)$ & $34(37.4 \%)$ \\
\hline Male $(\mathrm{N}=59)$ & $8(13.6 \%)$ & $14(23.7 \%)$ & $6(10.2 \%)$ & $31(52.5 \%)$ \\
\hline Total $(\mathrm{N}=150)$ & $29(19.3 \%)$ & $32(21.3 \%)$ & $24(16.0 \%)$ & $65(43.3 \%)$ \\
\hline
\end{tabular}

Not significant $p<0.05$ 
Figure 1: Distribution of sample according to DAI severity level

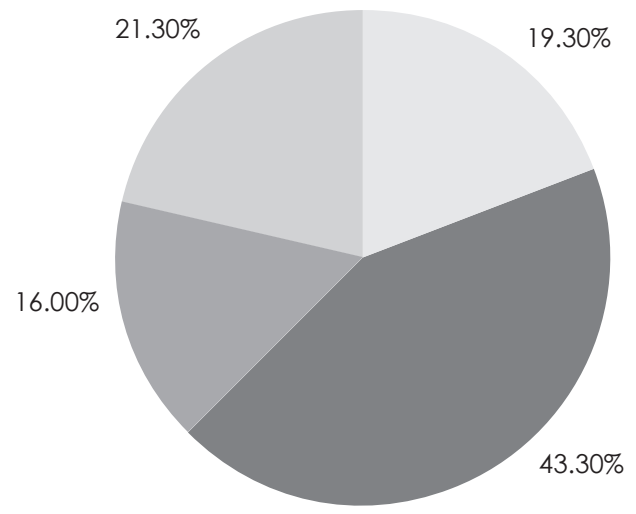

Very severe (handicapping) malocclusion

Definitive malocclusion

Severe malocclusion
Figure 2: Comparison of gender with respect to DAI score

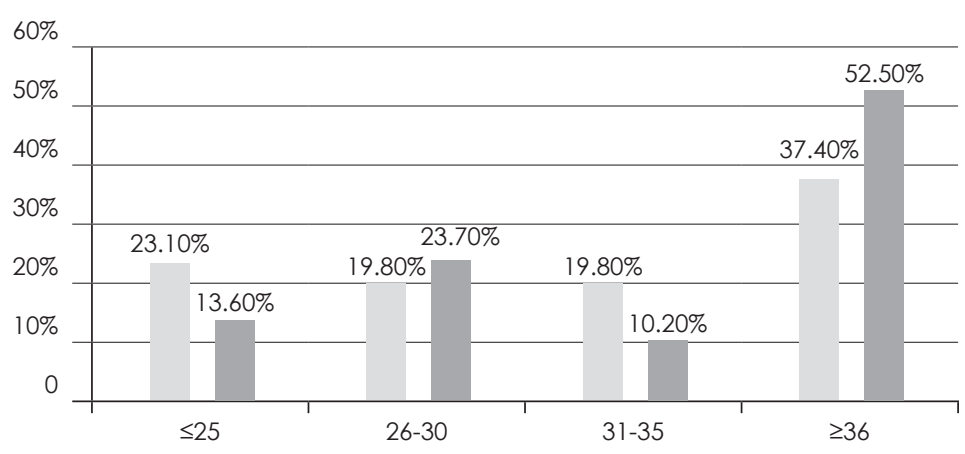

Female
Male
Normal or minor malocclusion

\section{DISCUSSION}

Dental Aesthetic Index was used in the present study for its simplicity, reliability and validity; which has not been used on Nepalese samples in the past. Standard method without any modifications or adaptations was used in the study. The DAl scores in our sample ranged from 19-62, with the mean DAl score 34.59 indicating that the majority of orthodontic patients having severe or very severe malocclusions with mandatory treatment need. The mean DAl score in Peruvian samples was 28.87; indicating that lesser Peruvian samples having severe or very severe malocclusion. ${ }^{8}$ On dichotomizing the DAI scores as "no need for treatment DAI $\leq 25$ " and "in need of treatment DAI > 25"; nearly $81 \%$ Nepalese patients required orthodontic treatment and $19 \%$ required little or no treatment. Among similar studies; $89 \%$ Rwandese samples required orthodontic treatment,' almost $60 \%$ Peruvian young adults required orthodontic treatment, ${ }^{8}$ and $97 \%$ Indian patients required orthodontic treatment. ${ }^{10}$

The distribution of severity of malocclusion in Nepalese orthodontic patients is comparable to other population samples. The present study found $43.3 \%$ Nepalese orthodontic patients having very severe or handicapping malocclusion, while Goyal et al found 51\% Rwandese samples having handicapping malocclusion.' Poonacha et al found $82 \%$ of the Indian sample having severe or very severe malocclusion. ${ }^{10}$ Among the occlusal traits, incisal crowding, anterior irregularity and increased overjet were the most frequently observed orthodontic problems; while anterior open bite and mandibular overjet (anterior crossbite) showed low prevalence rates in Nepalese subjects.

Despite incorporating 10 major occlusal traits, DAI cannot be considered as a sole criterion to determine the orthodontic treatment need. DAl considers crowding and spacing in incisal region only, while crowding in canines and premolar region is also esthetic concern. DAI has the limitation to exclude other occlusal traits that are equally significant in concluding the severity level of malocclusion and treatment plan. Buccal cross bite, labially or palatally erupted canines and premolars, midline discrepancy, deep and traumatic bite, supernumerary teeth, extracted posterior teeth with mutilated dentition, posterior open bite, cleft palate problems etc. are some of the malocclusions that can affect the orthodontic treatment need. " In addition, DAl component measurements are made using a millimeter probe, even a small error can have an exaggerated effect on the cumulative DAl score because of the score multiplied with regression coefficient. 6,10 In fact, many of these shortcomings are addressed by Index of Orthodontic Treatment Need (IOTN) with dental health and aesthetic components with greater reliability and wider applicability. ${ }^{2}$ However, DAI can be used directly in patients' mouth, even a trained dental auxiliaries can use it reducing the cost and reducing burden on orthodontist. 8.10

Being a developing country, Nepal does not have publicly funded dental treatment program or dental insurance policy to cover orthodontic treatment; people have to pay on out-of-pocket expenditure for their orthodontic treatment. On this scenario, the use of DAl as an epidemiological tool or a screening device shows a good promise to evaluate malocclusion severity and to prioritize treatment need among Nepalese population. Surveys on larger scale should be carried out in both community and clinical set-up involving government health service and dental institutions.

\section{CONCLUSION}

The highest prevalence of malocclusion severity among Nepalese orthodontic patient sample was 'very severe' or 'handicapping' malocclusion with mandatory need 
of orthodontic treatment. Male subjects had greater percentage of 'very severe' malocclusion compared to females. Malocclusion was characterized with relatively high frequency of incisal crowding, anterior incisal segments irregularity and maxillary overjet. Since many other occlusal traits were also found to be influencing the decision of orthodontic treatment need, DAl can be used as a screening tool rather than the decision making tool.

\section{REFERENCES}

1. Goyal S, Goyal S, Muhigana A. Assessment of malocclusion severity levels and orthodontic treatment needs using the Dental Aesthetic Index (DAI): A retrospective study. Rwa Med J. 2013; 70(3):20-7.

2. Cardoso C, Drummond A, Lages E, Pretti H. The Dental Aesthetic Index and Dental Health Component of the Index of Orthodontic Treatment Need as tools in epidemiological studies. Int J Environ Res Public Health 201 1; 8(8):3277-86.

3. Borzabadi-Farahani A. An insight into four orthodontic treatment need indices. Progress Orthod. 2011;12(2):132-42.

4. Gupta A, Shrestha RM. A review of orthodontic indices. Orthod J Nep. 2014; 4(2):44-50.

5. Danyluk K., Lavelle C, Hassard T. Potential application of the Dental Aesthetic Index to prioritize the orthodontic service needs in a publicly funded dental program. Am J Orthod Dentofac Orthop. 1999; 116(3):279-86.

6. Hamamci N, Basaran G, Uysal E. Dental Aesthetic Index scores and perception of personal dental appearance among Turkish university students. Euro J Orthod. 2009; 31 (2):168-73.

7. Uzuner FD. Angle's Classification versus Dental Aesthetic Index in evaluation of malocclusion among Turkish orthodontic patients. J Dent App. 2015; 2(3):168-73.

8. Eduardo B; Carlos F. Orthodontic treatment need in Peruvian young adults evaluated through Dental Aesthetic Index. Angle Orthod. 2006; 76(3):417-21.

9. Cons NC, Jenny J, Kohout FJ, Songpaisan Y, Jotikastira D. Utility of the Dental Aesthetic Index in industrialized and developing countries. J Pub Health Dent. 1989; 49:163-6.

10. Poonacha K, Deshpande S, Shigli A. Dental Aesthetic Index: Applicability in Indian population: A retrospective study. J Ind Soc Ped Prev Dent. 2010; 28(1):13-7.

11. Babu V, Gopu H. Assessment of orthodontic treatment needs according to Dental Aesthetic Index. J Dent Sci Res. 2011; 2(2):9-13.

12. Shrestha S, Shrestha RM. Index of Orthodontic Treatment Need in a referred Nepalese population. Orthod J Nep. 2012; 2(1):9-15. 